\title{
PENYEGARAN KADER LANSIA \\ DI DESA PAGARUYUNG KEC. TAPUNG KAB. KAMPAR
}

Rika Andriyani, Miratu Megasari, Een Husanah

STIKes Hang Tuah Pekanbaru

\begin{abstract}
Posyandu for elderly, a container formed by the community with the aim of being able to improve the health status of the elderly. According to the Indonesian Ministry of Health (2006), one of the goals of establishing posyandu for elderly is to increase the reach of elderly health services in the community, so that health services are formed according to the needs of the elderly In the village of Pagaruyung Kec. Tapung district. Kampar, there is a posyandu for the elderly, which at this time rarely does the activities of the elderly poyandu. The number of elderly people in Pagaruyung village is 120 people. The posyandu activities for the elderly are limited to measuring TB and weighing weight and simple medication. This activity is not routinely carried out. because it is necessary to refresh the elderly posyandu involving elderly posyandu cadres in Pagaruyung village, Tapung sub-district. The method used in this activity is demonstration and counseling. The activity was carried out in September 2017. The results of this activity were the increased motivation of elderly posyandu cadres to be active in posyandu activities. Cadres are committed to actively developing posyandu for elderly in Pagaruyung Village, with leaflets on elderly nutrition that can be used as material in providing counseling for the elderly later. It is hoped that this activity can be carried out in a sustainable manner so that the cadres will have more knowledge and skills
\end{abstract}

Key word: cadres, elderly Posyandu,

\begin{abstract}
ABSTRAK
Posyandu lansia wadah yang dibentuk oleh masyarakat dengan tujuan untuk dapat meningkatkan derajat kesehatan lansia. menurut Depkes RI (2006), tujuan pembentukan posyandu lansia sebagai salah satunya adalah Meningkatkan jangkauan pelayanan kesehatan lansia di masyarakat, sehingga terbentuk pelayanan kesehatan yang sesuai dengan kebutuhan lansia. Di desa pagaruyung kec. Tapung kab. Kampar, terdapat posyandu lansia yang pada saat ini jarang dilakukan kegiatan-kegiatan poyandu lansia. Jumlah lansia di desa pagaruyung berjumlah 120 orang. Kegiatan posyandu lansia yang dilakukan terbatas kepada pengukuran TB dan penimbangan BB serta pengobatan sederhana. Kegiatan ini tidak rutin dilakukan . oleh karena perlu dilakukan penyegaran posyandu lansia yang melibatkan kader-kader posyandu lansia di desa pagaruyung kecamatan Tapung. Metode yang digunakan dalam kegiatan ini adalah demonstrasi dan penyuluhan. Kegiatan dilakukan pada bulan september 2017. Hasil Kegiatan yang dilakukan ini adalah Meningkatnya motivasi kader posyandu lansia untuk aktif dalam kegiatan posyandu. Kader berkomitmen untuk aktif mengemabngkan posyandu lansia di Desa pagaruyung, adanya leaflet tentang gizi lansia yang dapat dijadikan bahan dalam memberikan penyuluhan pada lansia nantinya. Diharapkan kegiatan ini dapat dilakukan secara berkelanjutan sehingga semakin banyak pengetahuan dan keterampilan yang dimiliki Kader
\end{abstract}

Key word : Kader, Posyandu lansia, 


\section{Pendahuluan}

Posyandu lansia merupakan bentuk perwujutan pelaksanaan pengembangan diri dari program pemerintah yang menitikberatkan pada kesehatan lansia dan meningkatkan kwalitas hidup dan kesejahteraan lansia, dengan melibatkan masyarakat usia lanjt, tokoh desa, keluarga dan organisasi sosial (Kemenkes RI, 2014). Dalam pelaksanaannya posyandu lansia dijalankan oleh kader. Kader Posyandu adalah ujung tombak pemerintah paling depan di bidang kesehatan untuk menurunkan angka kematian ibu dan bayi serta memperpanjang angka harapan hidup masyarakat.

Posyandu lansia wadah yang dibentuk oleh masyarakat dengan tujuan untuk dapat meningkatkan derajat kesehatan lansia. menurut Depkes RI (2006), tujuan pembentukan posyandu lansia sebagai salah satunya adalah Meningkatkan jangkauan pelayanan kesehatan lansia di masyarakat, sehingga terbentuk pelayanan kesehatan yang sesuai dengan kebutuhan lansia. Di Indonesia sendiri, saat ini telah terjadi peningkatan jumlah penduduk lansia yang tadinya berjumlah 18 juta jiwa di tahun 2010, sudah bertambah menjadi 25,9 juta jiwa pada tahun 2019. Jumlah warga lansia pun diperkirakan akan terus meningkat hingga mencapai 48,2 juta jiwa di tahun 2035 .

Keberadaan posyandu lansia Diharapkan tidak hanya membahas persoalan kesehatan saja, namun juga perlu perluasan peran para kader posyandu dalam aspek-aspek kehidupan lainnya. Seringnya kontak pertemuan antara para kader posyandu dengan masyarakat biasa memberikan pencerahan yang lain mengenai kehidupan bermasyarakat selain membahas masalah kesehatan. Perluasan peran kader Posyandu yang dimaksud adalah berfikir tentang kehidupan dimasa mendatang dan kehidupan social tentang bagaimana membina hubungan social diantara anggota keluarga, hubungan social keluarga dengan masyarakat sekitar dan hubungan social masyarakat dengan pemerintah.

Ketika pertemuan rutin, kader posyandu diharapkan dapat membantu pemerintah dalam memberikan pencerahan kepada masyarakat untuk melakukan hal-hal yang bersifat positif. Banyak hal positif yang dapat diperoleh dari pertemuan-pertemuan antara kader posyandu dengan masyarakat. Pertemuan posyandu selain menyangkut persoalan dalam hal kesehatan dapat juga berbagi 
pengalaman dan pengetahuan disamping sebagai ajang silaturahmi antara masyarakat. Momentum pertemuan posyandu biasa dijadikan untuk meningkatkan wawasan dan pengetahuan dan berbagi pengalaman positif guna mewujudkan masyarakat yang cerdas dan berwawasan yang bermanfaat bagi kehidupan kader posyandu dan masyarakat pada umumnya. (Khazalik: 2015).

Kader-kader yang menjadi peserta diberikan pembekalan mengenai bagaimana cara menangani para lansia. Bagaimana cara menangani lansia dengan keadaan fisik dan daya tahan tubuh yang mulai melemah, membangkitkan gairah para lansia agar tidak terlalu memikirkan masalah kehidupan yang rumit di usia senja, menyadarkan para lansia tentang pentingnya menjaga kesehatan diri, bagaimana cara menyikapi lansia dengan baik mengingat ketika memasuki umur yang sudah dikategorikan lansia perasaan seseorang akan menjadi lebih sensitif .

Di desa pagaruyung kec. Tapung kab. Kampar, terdapat posyandu lansia yang pada saat ini jarang dilakukan kegiatan-kegiatan poyandu lansia. Jumlah lansia di desa pagaruyung berjumlah 1200 orang. Kesehatan lansia menjadi tanggung jawab bersama. Lansia harus dapat hidup berkualitas. Kegiatan lansia yang dilakukan terbatas kepada pengukuran $\mathrm{TB}$ dan penimbangan $\mathrm{BB}$ serta pengobatan sederhana. Kegiatan ini tidak rutin dilakukan . oleh karena perlu dilakukan penyegaran posyandu lansia yang melibatkan kader-kader posyandu lansia di desa pagaruyung kecamatan Tapung

\section{Rumusan Masalah}

Mengingat peran kader sangat penting halnya untuk membentuk sebuah desa dengan kualitas kesehatan warga terjamin. Sehingga pencegahan kemungkinan-kemungkinan buruk yang dapat terjadi pada kesehatan terutama pada lansia dan juga balita dapat segera ditangani oleh para kader sebagai tindakan pertolongan pertama. Maka Perlu dilakukan penyegaran Posyandu lansia di desa Pagaruyung

\section{Tujuan Penulisan}

Untuk mengaktifkan kembali posyandu lansia dan untuk meningkatkan pengetahuan Kader Lansia tenatng Status Gizi pada Lansia di desa pagaruyung Kabupaten Kampar

\section{Metode Kegiatan}

1. Demonstrasi dalam pelatihan kader, dimana para kader mengikuti 
pelatihan mengenai kader lansia dan Posyandu Lansia.

2. Ceramah interaktif dilakukan setelah membagikan leaflet mengenai Posyandu Lansia yang dapat meningkatkan pemahaman para kader.

3. Membagikan modul setelah penyuluhan dilakukan agar materi yang di sampaikan dapat di baca kembali di rumah.

\section{HASIL DAN PEMBAHASAN}

\section{Hasil}

Kegiatan pengabdian masyarakat dilaksanakan pada bulan September 2017. Kegiatan pengabdian masyarakat ini melibatkan kader kesehatan, tokoh masyarakat, dosen dan mahasiswa d3 kebidanan STIKes Hang Tuah. Hasil kegiatan mengacu pada rencana kegiatan yang telah ditentukan sebelumnya. Kegiatan yang telah dilaksanakan meliputi:, 1) Penyuluhan tentang posyandu lansia kaitannya dengan peran kader, 2) Pelatihan dan penyegaran kader kesehatan tentang status gizi pada lansia 3) pembuatan media promosi (leaflet, lembar balik), tentang dizi seimbang bagi lansia

Berdasarkan wawancara, tanya jawab dan pengamatan langsung selama kegiatan berlangsung, kegiatan pengabdian pada masyarakat ini memberikan hasil sebagai berikut 1) Meningkatnya motivasi kader posyandu lansia untuk aktif dalam kegiatan posyandu. 2) Meningkatkanya pengetahuan kader lansia tentang status gizi lansia serta nutrisi yang harus dipenuhi oleh lansia, 3) adanya leaflet tenatng gizi lansia yang dapat dijadikan bahan dalam memberikan penyuluhan pada lansia nantinya.

\section{Pembahasan}

Sejumlah kader lansia mengikuti kegiatan penyegaran posyandu lansia yang diadakan di desa pagaruyung kec. Tapung kabupaten kampar. Melalui kegiatan ini diharapak kegiatan posyandu lansia dapat berjalan sesuai dengan jadwal yang telah di tetapkan oleh masyarakat yakni 1 bulan sekali. Kegiatan penyuluhan dan kemitraan kader Lansia mengenai penyegaran kader Lansia sebagai upaya untuk mengaktifkan kembali posyandu lansia yang dilaksanakan di Posyandu Desa Pagaruyung Kecamatan Tapung Kabupaten Kampar berjalan dengan baik dan sesuai rencana. Hal ini terbukti dari antusiasme para kader saat mengikuti jalannya kegiatan dan aktivitas para 
kader untuk bertanya tentang Gizi pada Lansia. Para kader benar-benar memperhatikan saat pemateri memberikan penyuluhan dan pelatihan tentang Status Gizi pada Lansia. Kader adalah kelompok anggota masyarakat yang bersedia, mampu dan memiliki waktu untuk mengabdikan diri menjadi Kader posyandu lansia secara sukarela (Permendagri 2011), kader posyandu lansia adalah dari, oleh dan untuk masyarakat bekerja secara sukarela bertugas untuk membantu dan memastikan kelancaran pelaksanaan posyandu lansia (Kolifah, 2016).

$$
\text { Perubahan prilaku sangat }
$$
diharapkan dari kegiatan ini, metode penyuluhan yang dipilih merupakan salahb satu metode yang dapat menrubah perilaku seseoranga. Menurut McKenzie, 2005 dalam Yulizawati, dkk 2016, untuk mencapai perubahan perilaku, ada dua cara pendekatan yang dapat dilakukan yaitu secara pendekatan pendidikan dan secara paksaan. Pendidikan merupakan upaya pembelajaran pada masyarakat agar mau melakukan tindakan-tindakan yang dapat memelihara kesehatannya yang biasanya proses ini memerlukan waktu yang relatif lama, tetapi dapat bertahan lama dalam diri individu. Paksaan atau tekanan Untuk yang diberikan pada individu atau masyarakat agar terjadi perubahan perilaku tidak terjadi karena proses pembelajaran, pemahaman, dan kesadaran sehingga tidak akan bertahan lama.

\section{Kesimpulan}

Berdasarkan kegiatan yang telah dilaksanakan, maka dapat disimpulkan beberapa hal sebagai berikut :

1. Daya serap Kader Lansia terhadap materi kegiatan cukup baik.

2. Sikap antusias dan rasa ingin tahu Kader Lansia cukup besar, ini terlihat dari keinginan untuk bertanya tentang materi yang diberikan yaitu Status Gizi pada Lansia.

3. Terjalinnya keakraban dan suasana kekeluargaan sesama peserta maupun dengan para pemberi materi.

\section{Saran}

Setelah selesai kegiatan penyuluhan dan pelatihan tentang Status Gizi pada Lansia ini, diharapkan ada tindak lanjut sebagai berikut :

1. Adanya kegiatan serupa secara berkelanjutan dengan materi atau informasi-informasi lain yang lebih aktual, sehingga pengetahuan dan keterampilan para kader Posyandu dapat terus ditingkatkan yang pada akhirnya pelaksanaan layanan 
kesehatan pada Lansia bisa semakin baik.

2. Perlunya penyebarluasan kegiatan di wilayah lainnya sebagai upaya pemerataan pendidikan masyarakat dalam rangka meningkatkan kemampuan dan kemandirian masyarakat di bidang kesehatan.

\section{Daftar Pustaka}

Depkes RI. 2006. Pedoman pelatihan kader kelompok usia lanjut bagi petugas kesehatan. Direktorat kesehatan keluarga.

Kementrian Kesehatan, R.I., (2014), Pedoman pengelolaan posyandu ,Departemen Kesehatan Republik Indonesia.
Kholifah, S.N. (2016). Modul Bahan Ajar Cetak Keperawatan Gerontik. Jakarta : Kemenkes RI Pusdik SDM Kesehatan

Kemenkes. (2016). Infodatin Situasi Lanjut Usia (Lansia) di Indonesia. Jakarta: Pusat Data dan Informasi Kemenkes RI

Yulizawati, 2016, Pengaruh Pendidikan Kesehatan Metode Peer Education Mengenai

Skrining Prakonsepsi Terhadap Pengetahuan Dan Sikap Wanita Usia

Subur Di Wilayah Kabupaten Agam Tahun 2016. Jurnal. Diakses tanggal 08 Septermber 2017 